\title{
The effect of multi parameter changes of arch bridge on buckling analysis of arch bridge
}

\author{
Huang Lin,Tongfa Deng, Qiang Zheng and Rui Liao \\ School of Archietctures and Surveying\&Maping Engineering, Jiangxi University of Science and Technology, Ganzhou \\ 341000, China
}

Keywords: multi parameter, bridge stability, buckling analysis, instability mode, deck arch bridge

\begin{abstract}
Based on the data of a arch bridge that lready built up, the finite element analysis model is established by finite element analysis software called Midas Civil. The buckling mode and buckling characteristics of the bridge are analyzed. The following operations changes are performed: the width of the arch rib, the cross section of the arch rib, the cross section of the column, the relative position of the column in the arch rib, etc.he finite element analysis model is established to study the buckling mode of arch bridge under different arch bridge parameters. In the design of arch bridge, the reasonable analysis of the arch bridge is considered. The results show that the stability coefficient of the arch bridge is not linear, but a nonlinear effect. There is a reasonable choice of the multi parameters of the arch bridge, which is related to the use of the concrete arch bridge, the terrain conditions and so on. This paper is to make a basic research to provide some theoretical basis for the design of the arch bridge with reasonable parameters.
\end{abstract}

\section{Introduction}

Taking an arch bridge as a beautiful bridge shape ,used by many bridge engineers in the history of bridge construction. On the one hand, due to its beautiful shape, and can be well coordinated with the surrounding environment. On the other hand,because old arch bridge as a bearing structure, as long as the good compression performance has condition to become a prerequisite for arch bridge construction materials.And stone material as the bearing capacity of good material,it is convenient to take the promotion of arch bridge. The most famous Chinese arch bridge is Zhaozhou Bridge, it is a typical deck arch bridge, although it is old, still in use, which is sufficient to explain the stability of this shape of bridge. The study of the arch bridge has always been a keen to the engineering research personnel.Chen $\mathrm{G} \mathrm{H}^{[1]}$ analysed linear and nonlinear of arch bridge, and summarizes some characteristics of nonlinear.Huo $\mathrm{X} \mathrm{J}^{[2]}$ discussed the nonlinear characteristics of the arch bridge,especially for the nonlinear characteristics of the special-shaped arch bridge.Zhu $\mathrm{K} Z^{[3]}$

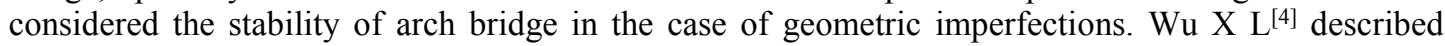
nonlinear behavior of arch bridge when it use stiff skeleton as it's load-bearing structure.But in the research field of arch bridge,the concrete influence of all parameters on the buckling analysis of arch bridge is not discussed.In this paper,mainly do theoretical study and numerical simulation on the basis of this aspect.nowadays, with the progress of science and technology and the invention of concrete filled steel tube, the bearing capacity of arch bridge has been widened.In succession, there is a 
medium bearing and a lower bearing type of arch bridge, but the upper deck arch bridge still has its unique position.More famous deck type arch bridge is changjiang river bridge in wanxian of chongqing city,a bridge has a 420m mainspan, Yajisha bridge with a 360m mainspan in Guangdong province,Beipan river bridge with a 236m mainspan in Guizhou province etc.Reinforced concrete arch bridge has great competition in the moder long-span arch bridge, and the ribbed-box arch bridge is the common kind in the arch bridge. This article mainly research by ribbed-box arch bridge. The section forms that varies considerably depending on topography, span of arch rib and prevailing level. Between arch ribs and bridge panel connected by columns.By controlling the other parameters constant, this paper mainly change the arch of a parameter to study under the condition of a certain parameter change buckling mode change situation of arch bridge, under the premise to ensure stability of the bridge is a reasonable choice of parameters of arch bridge.

\section{The finite element modeling}

\subsection{The engineering general situation}

A bridge has been built on the reinforced concrete of bearing type ribbed-box arch bridge is a typical deck type arch bridge.It is located in the mountains where has a river flow through, considering the problems of the construction of the piers, chose the arch bridge, this also is many mountains in the choice to consider the reason of the arch bridge. The deck width is $10 \mathrm{~m}$,net span if $150 \mathrm{~m}$,net sagittal height is $30 \mathrm{~m}$.arch axis of bridge is catenary(catenary coefficient:1.988). The main arch ring cross section is single box section double room, with four rectangular columns and cover beam connections, not set transverse connection, only through the upper plate beam to make four columns to form a whole. This bridge used simple beam to construct it's structure on the arch,which are all precast $\mathrm{T}$ shape beam.

\subsection{Create the finite element model}

Based on Midas Civil powerful finite element analysis, the use of it to establish finite element model of arch bridge.Because the main purpose is to analyze the buckling of arch bridge modal, so the main consideration when modeling the main part of the arch bridge, ignoring the approach span section.Main arch on reinforced concrete components and mainspan floor system component by using the three dimensional space beam element model were divided into 645 units and 475 nodes.Along the bridge for the $\mathrm{x}$ direction, cross the bridge for the $\mathrm{y}$ direction, perpendicular to the bridge deck for $\mathrm{z}$ direction, according to the related parameters to establish the three dimensional space finite element model of arch bridge.Finite element model is shown in figure 3.

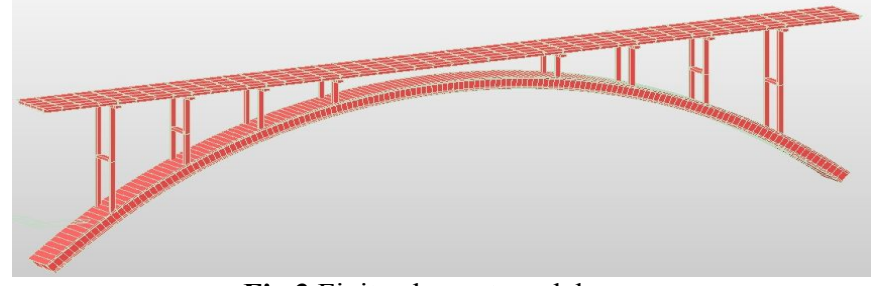

Fig.3 Finite element model

\section{The finite element modeling}

\subsection{Create the finite element model}

If arch outside surface not under lateral load, the effect of the transverse stiffness of smaller arch, when the arch was under in-plane loading reached the critical value of the arch axis to the 
vertical plane deviation and appear when the roll, the branch instability appeared in the process of balance. When under the critical state of stress is less than the yield stress, is the face external elastic curve, because it is a problem of space, so the exact solution is more difficult, can only approximate solutions.Flat arch axis, the buckling instability is roll more instability, the difference is symmetry instability or antisymmetry buckling.Arch bridge is a spatial curve when after the roll. Which displacement and the geometric relation can be obtained by the curvilinear coordinates.Its computation formula as shown in type (1):
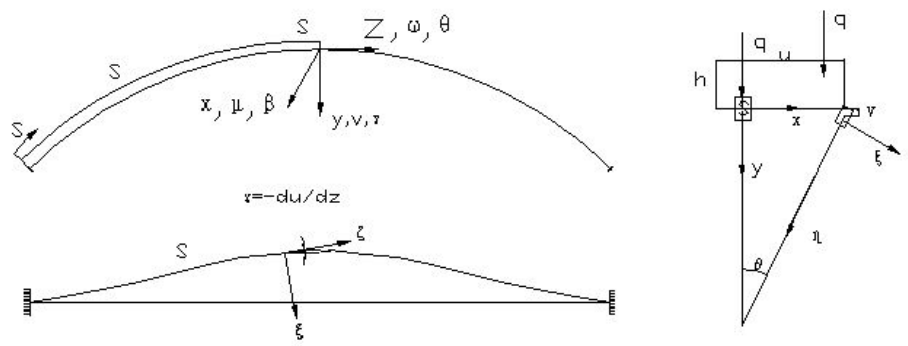

The plane arch in-plane differential process when it flexural torsional buckling:

$$
\left.\begin{array}{l}
-\left[E I\left(\dot{u}-\frac{\theta^{\prime}}{R}\right)\right]^{\prime}+\left[\frac{G I_{d}}{R}\left(\theta^{\prime}+\frac{u^{\prime}}{R}\right)\right]^{\prime}-\left[\frac{E I_{w}}{R}\left(\theta^{\prime}+\frac{u^{\prime}}{R}\right)^{\prime}\right]^{\prime}+N\left(-u^{\prime}+\frac{u^{\prime}}{R}\right)-q_{\xi}=o \\
{\left[G I_{d}\left(\theta^{\prime}+\frac{u^{\prime}}{R}\right)^{\prime}\right]^{\prime}-\left[E I_{w}\left(\theta^{\prime}+\frac{u^{\prime}}{R}\right)^{\prime}\right]^{\prime}+\frac{E I_{y}}{R}\left(\dot{u}-\frac{\theta^{\prime}}{R}\right)+m_{\xi}=0}
\end{array}\right\}
$$

\subsection{Create the finite element model}

\section{(1) Change the width of the arch rib}

The main method is to keep the arch of the other parameters constant, change the width of the arch rib, in order to further analyzing the buckling characteristics of arch bridge.Keep the arch span $150 \mathrm{~m}$, the arch rib section height unchanged, only change the width of the arch rib, to achieve the goal of different width span ratio.Itself, the width of the bridge arch rib is $6 \mathrm{~m}$, then respectively set the arch rib width is $5 \mathrm{~m}, 5.5 \mathrm{~m}, 6.5 \mathrm{~m}, 7 \mathrm{~m}$ arch buckling analysis of four cases. Then a comparison with the original arch bridge. Specific data as shown in figure 4 :

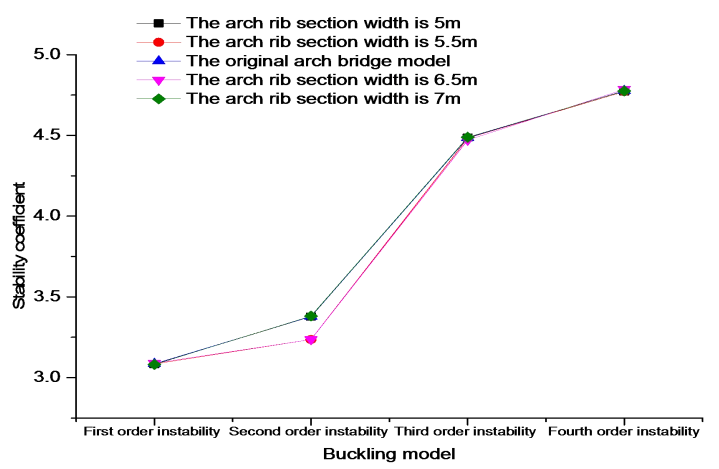

Fig.4 Comparison of the stability coefficient of different arch rib section

From figure 4 of the stability factor of the arch bridge under different arch rib width contrast can be seen in the four kinds of arch rib width change, under the condition of stability factor change is not big, and close to the original arch bridge model.It's enough to see the original arch bridge model when choosing arch rib width has chosen the reasonable width, and in the case of arch rib width change is not big, affect is the basic analysis of the stability of the arch bridge. This also verify the stability of arch rib to get a lot of promise.Based on this result, when choosing arch rib width should be properly by precise calculation of width, considering the structure safety and can decrease the cost and achieve great price.

(2) Change the lateral stiffness of arch rib 
Lateral stiffness of the arch rib is not only related to materials used in the arch rib, also related to the particular form of arch rib section.By the original arch bridge arch rib section of the form we can use some measures to change its lateral stiffness, the up and down in the roof and partition of arch rib is what we can consider to change the parameters of arch rib.In fluctuation of roof respectively based on the original arch bridge arch rib width $0.25 \mathrm{~m}$ set respectively $0.3 \mathrm{~m}$ and $0.35 \mathrm{~m}$ comparing two kinds of thickness.And partition based on the original arch bridge in the plate thickness of $0.2 \mathrm{~m}$, respectively set up $0.25 \mathrm{~m}, 0.3 \mathrm{~m}$ comparing two kinds of thickness. The results after specific parameters changed as shown in figure 5:

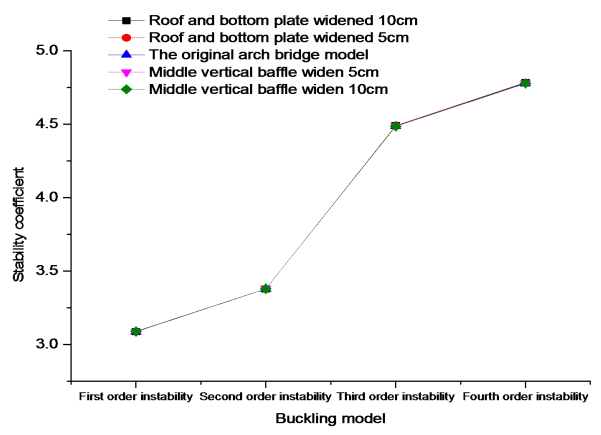

Fig.5 The stability coefficient of the lateral stiffness of the arch rib

Can be seen from the figure 5 as the growth of the order number, number increases present single direction stability, and under the condition of parameter change, the stability coefficient between different parameters did not show obvious differentiation.By contrast can be found in the first order instability and second-order buckling stability coefficient under basically did not change, and in the third order instability and a slight change to fourth order stability.It also suggests that the transverse stiffness of concrete in the case of small change in a second order modal not show obvious differentiation, and with the increase of the buckling mode will appear more serious changes.Because of high order buckling mode has higher request to the structure, so even subtle differences in high order instability will also is very obvious. This requires engineering technical personnel must carefully when considering the complex engineering bridge calculation parameters, be sure to get the reasonable value range.

\section{(3) change the size of the column section (mainly changed the size of the cross section)}

The original model of arch bridge cross section width of $0.45 \mathrm{~m}$. Now cross section width were taken into $0.35 \mathrm{~m}, 0.4 \mathrm{~m}, 0.5 \mathrm{~m}, 0.55 \mathrm{~m}$ four cases of arch bridge, such as buckling mode were compared with the original arch bridge modal, look at the parameters under the condition of buckling of arch bridge modal for the influence of the geometry.Specific contrast situation as shown in figure 6:

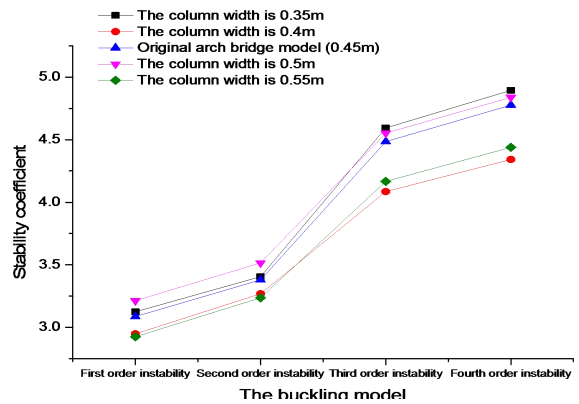

Fig.6 The stability coefficient of arch bridge with the change of the width of the column section

Through comparing can be found in figure 6 , as in the previous two parameters, the buckling mode under different parameters presented obvious differentiation, and more obvious. This shows that the parameters on the buckling of arch bridge modal has great influence, and, with the increase of order differentiation become clearer. Can be seen from the figure 6 is the width of $0.5 \mathrm{~m}$, the stability coefficient of the linear integral over the original arch bridge, just as the order number increase, to be near the original arch bridge linear trend; When the width is $0.55 \mathrm{~m}$, stability coefficient of the linear 
down to the bottom of the whole line instead of the original arch bridge;And width of $0.35 \mathrm{~m}$ and 0.4 $\mathrm{m}$ also presents the differentiation, the whole line above, in the original arch bridge which is a whole line below the original arch bridge. Which can account for the width change is not linear to the arch of the buckling mode, choose reasonable pillar width of cross section need considering comprehensive situations, nonlinear effects of the width of the column section will undoubtedly make the important factor that cannot be ignored.

\section{(4) Change the columns and the relative position of the arch rib}

Based on the original column in the relative position of the arch rib arch bridge design, through the relative position of pillar set for the original offshoring move and operation to study the buckling modes of the arch bridge, the specific data as shown in figure 7 :

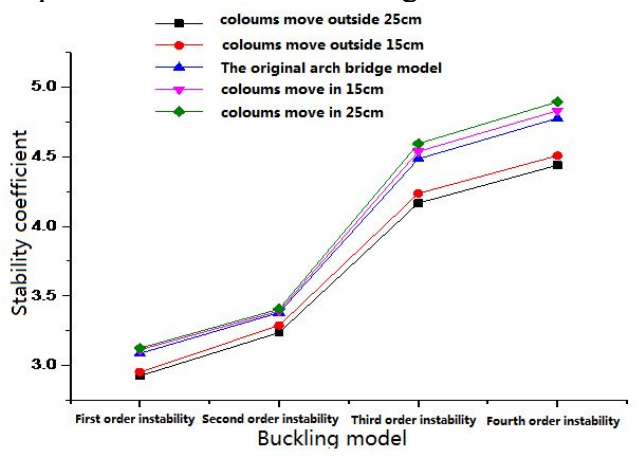

Fig.7 The stability coefficient of arch bridge with the change of the position of the column relative to the design

Through this parameter can be seen from the figure 7 data changes significantly different from the former two kinds of circumstances, but with the changes in the pillar width of cross section and a little different.When offshoring stud $15 \mathrm{~cm}$ below the line integral in the original arch bridge line, and divide; When offshoring post $25 \mathrm{~cm}$, also on the original arch bridge below the line.Offshoring it with $15 \mathrm{~cm}$ of differentiation is not obvious at first, and when the order number increase differentiation become clearer. Which further proves the high order to specific parameters of the structure and instability of requirements.Pillar in moving within $15 \mathrm{~cm}$ and $25 \mathrm{~cm}$ above the line in the original arch bridge, offshoring and roughly similar.Offshoring from figure 7 also found pillar relatively within the column is compared with the original arch bridge linear differentiation are relatively obvious, it also can see the importance of the relative position of the mast in the arch rib.

\section{Conclusion}

Through the theoretical knowledge of buckling is discussed, and the establishment of the finite element model can know the bearing type arch bridge conform to the related characteristics of stability.Under the first order buckling instability, main show is symmetric tilt under quadratic performance for antisymmetric lateral buckling.Arch bridge bearing type in order to further to test under the condition of the various parameters change the arch buckling mode, buckling modal for arch bridge has a better understanding, first from the perspective of a single parameter change, change the arch width span ratio respectively, box-type structure of baffle plate and the thickness of the roof and floor, column cross-section the size of the columns in the arch rib buckling analysis was carried out on the arch bridge such as the change of the relative position. Then select two groups is discussed under the coupling between the parameters of buckling analysis of arch bridge with single parameter change under the influence of the buckling analysis of comparison.And get the following conclusions:

(1) Through the modeling data and theoretical analysis of the contrast, in line with the theory of train of thought, show that model is in conformity with mechanical characteristics.

(2) To control the other parameters constant, focus on changing one parameter to verify that this parameter change the buckling mode under the condition of arch bridge as well as the comparison with the original bridge. Through change edge width span ratio of arch rib, lateral stiffness of the arch 
rib, column section size, post four kinds of circumstances such as the change of the relative position of the arch rib to study.From the final results indicate that either way, the buckling mode of arch bridge is not linear, but nonlinear.But not every kind of parameter changes of buckling modes are compared with the original bridge has a significant change, such as the width of the arch rib section and lateral stiffness of the arch rib, when they change is fundamental to the buckling of arch bridge is not big impact analysis.And the width of the column section and the change of the relative position of the arch rib is the post buckling analysis of the arch bridge has a obvious effect.

(3) In this paper, we selected the buckling analysis of several groups of parameters on the arch bridge, the influence of the important parameters in the arch and far more than these, for selected groups of parameters is designed to do a basic research, with the single parameter in the arch buckling analysis of arch bridge and the influence of many parameters of arch bridge between buckling analysis of the coupling effects.For arch bridge of the parametric study, still need to do more work.But no matter how to change a parameter, in which the influence of the arch bridge has a reasonable range. In respect of buckling mode, the same is true of.Any impact parameter is not linear, based on this, choose reasonable bridge's sake should be considered in order to obtain high cost performance of bridge parameters match.

\section{References}

1. Chen G H,Zeng Y H,Jia H Y,etc. Large span cable stayed steel pipe concrete arch bridge buckling analysis[J].Journal of henan university,2010(5):538-541.

2. Huo X J,Han L Z.The geometric nonlinear analysis of special-shaped arch Bridges [J].highway traffic science and technology,2013(7):46-53.

3. Zhu K Z,Yi Z P,etc.Large span arch bridge considering the stability analysis of geometric defects[J].Journal of hunan traffic science and technology,2011(6):64-69.

4. Wu X L.Extra long-span concrete-filled steel tube strength frame arch bridge nonlinear behavior analysis[D].chengdu:Southwest jiaotong university, 2012.

5. Li G H.Stability and vibration of bridge structure[M].Beijing:China railway publishing house, 2002.

6. Shao X D.Bridge engineering[M].Beijing: people's traffic press, 2012.

7. Yu D,Zhang S M.Large-span half through bridge ultimate bearing capacity of concrete filled steel tube arch bridge[J].Journal of jilin university: engineering science, 2007,5(6): 1308-1312.

8. Wang S L,Yang T J.Skewness derrick anchorage zone of concrete filled steel tube arch bridge local stress and buckling analysis[J].Journal of Highway and Transportation Research and Development,2014(3): 151-153.

9. Zeng Z D,li C X,Zeng Y G.Research on concrete filled steel tubular arch bridge stability and ultimate bearing capacity and parameters analysis[J].Highway,2009,29(3):104-108.

10. Bergmeister Konrad, Capsoni Antonio, Corradi Leone, et al.Lateral elastic stability of slender arches for bridges including deck slenderness[J].Structural Engineering International:Journal of Lhe International Association for Bridge and Structural Engineering, 2009, 19( 2):149-154.

11. Guo $\mathrm{Z}$ H,Shi $\mathrm{X}$ D.Principle and analysis on the reinforced concrete[M].Beijing: Tsinghua university press, 2003.

12. Wu Y H,Ji X J,Guo J F,etc.Under the traveling wave effect to nonlinear seismic response analysis of long-span concrete-filled steel tube arch bridge[J].Highway traffic science and technology, 2011(1):80-85.

13. Chen F,He S H,Hu D L,etc.Leaning type steel tube concrete special-shaped arch bridge nonlinear stability analysis[J].Journal of xian building university of science and technology,2010.

14. Chen Y J.Steel tube concrete ribbed arch in-plane mechanical process research[D]:Fuzhou fuzhou university, 1998.

15. Zhao C J,Wang F J, Chen Q,etc.Large span concrete filled steel tubular arch bridge space stability analysis[J].Highway,2001,(2):15-18. 